\title{
Circumferential little finger nailplate
}

\author{
Achilleas Thoma MD FRCSC FACS, Iakovina Alexopoulou MD FRCPC \\ Department of Surgery, Division of Plastic Surgery and Department of Pathology, St \\ Joseph's Hospital and McMaster University, Hamilton, Ontario
}

\begin{abstract}
A Thoma, I Alexopoulou. Circumferential little finger nailplate. Can J Plast Surg 1995;3(3):161-162. This is a case report of a seven-year-old female who presented with a congenital anomaly of the little finger in which the nailplate was circumferentially covering the tip of the distal phalanx. There was a well-developed eponychial fold on the palmar aspect of the digit. This rare congenital 'clam nail deformity' may be the result of an insult to the zone of polarizing activity occurring late in the embryological development.
\end{abstract}

Key Words: Circumferential little finger nailplate, Clam nail deformity, Volar nailplate of the little finger

\section{Couche cornée circonférentielle du limbe unguéal de l'auriculaire}

RÉSUMÉ: Cet article présente le cas d'une enfant de sept ans ayant été amenée pour anomalie congénitale de l'auriculaire, sous la forme d'une couche cornée circonférentielle du limbe unguéal couvrant l'extrémité de la phalange distale. Un repli éponychial bien développé s'observait sur la face palmaire du doigt. Il s'agit d'une anomalie congénitale rare qui peut résulter d'une lésion à la zone d'activités polarisantes, survenant tard au cours du développement embryologique.

A seven-year-old girl was seen because of a congenital anomaly of the left little finger which included the circumferential development of the nailplate which tapered into a claw-like structure (Figure 1). She was catching it on clothes and often accidentally scratched her face, causing bleeding. Because of this and peer teasing, she wished to have it amputated.

An x-ray showed a pointed and tapered distal phalanx extending into this clawlike structure (Figure 2). 
Thoma and Alexopoulou

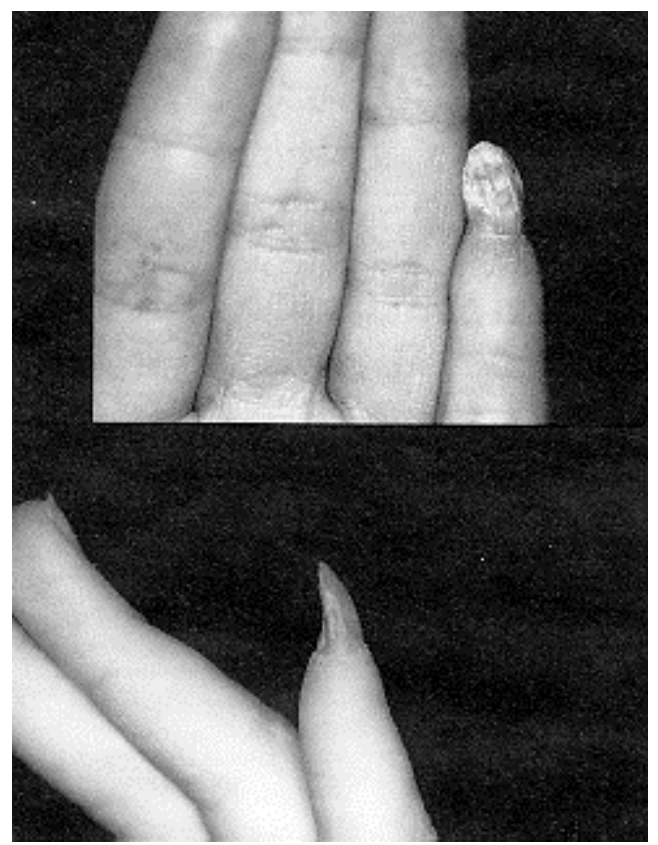

Figure 1) (Top) Palmar view of hand showing dorsal skin at tip of finger with well-developed eponychial fold with circumferential nailplate. (Bottom) Lateral view showing clearly the circumferential nature of this nail deformity

\section{Circumferential little finger nailplate}

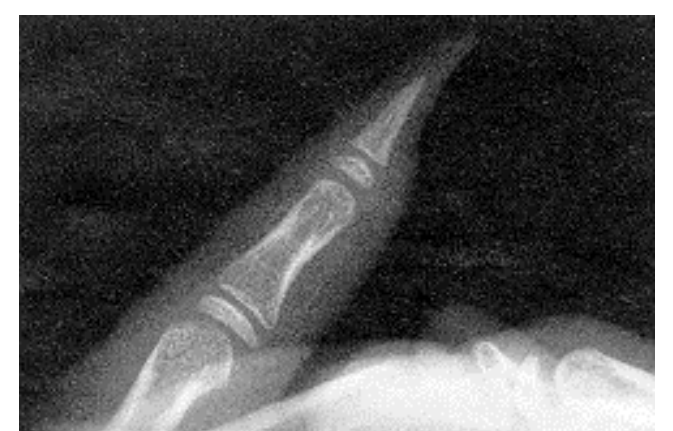

Figure 2) Lateral $x$-ray view of the digit showing a tapered distal phalanx sandwiched into this claw-like abnormal circumferential nailplate

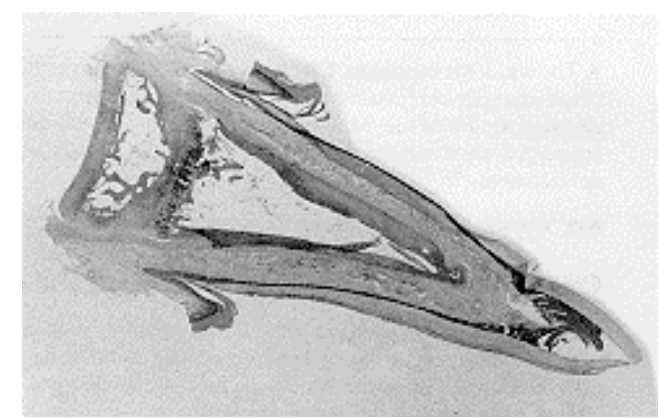

Figure 3) Histological specimen showing circumferential nail plate surrounding distal phalanx and well-developed eponychial folds on both dorsal and palmar surfaces

After considering the various options available, which included amputation or reconstruction, the patient and her parents opted for a simple amputation at the level of the distal interphalangeal (DIP) joint. The amputated distal phalanx measured $1.5 \mathrm{~cm}$ in length, $0.6 \mathrm{~cm}$ at its most proximal end, tapering to $0.3 \mathrm{~cm}$ at the distal end. The distal 1 $\mathrm{cm}$ of the phalanx was circumferentially covered by nail with a smooth surface and a pointy sharp end. Histological examination confirmed the nailplate to be truly circumferential (Figure 3). Within three weeks of the amputation, the patient was using this finger and was happy with the amputation stump rather than the deformity.

\section{DISCUSSION}

This particular nail abnormality is rare. Kalisman et al described a case with a similar fingernail and dorsal skin on the palmar aspect of the finger (1), involving a patient with partial deletion of chromosome 6 . A similar deformity affecting both little fingers was also reported by Keret and Ger in 1987 (2). This deformity of the little finger was aptly named 'clam nail deformity' by Kinoshita et al in 1991 (3). 
It is interesting that all previous reports on this abnormality in its full presentation appear to involve the little fingers only, similar to our case. No family history of similar abnormalities existed. It was not clear from the previous reports (1-3) whether the deformity represented truly a circumferential nail or in fact a duplication of the nail on both the volar and dorsal aspect since histology was not provided. In contrast to the reported cases, a histological examination was undertaken of the amputated specimen, confirming the clinical impression of the circumferential nature of the anomaly and the presence of the dorsal skin and a well-developed eponychial fold (Figure 3) on the volar aspect.

Advancement flap reconstruction was successfully used in Kinoshita's case in order to preserve the dorsal nail (3). A thenar flap reconstruction in stages or the free microvascular transfer of a partial toe could have been used to reconstruct the defect, but the patient and her parents declined.

Since this is a rare congenital abnormality, its cause is unknown. One could speculate that embryologically there was an insult to the zone of polarizing activity occurring late in the embryological development. The zone of polarizing activity is a specialized area in the thickened ventral ectoderm that originates in the axilla and progresses to the hand $(4,5)$. Experimentally, it was found that grafting cells from a normal polarizing zone to the dorsal position of a limb bud in chicks leads to a limb with mirror image structures (5). One can speculate that a mirror image duplication has occurred in the eponychial and nailplate structures which fused to give the circumferential clam-like fingertip.

ACKNOWLEDGEMENTS: The authors would like to thank Ms Sherry Calligan for typing and Ms Beth Tadeson BSc for her help in the preparation of the manuscript.

\section{REFERENCES}

1. Kalisman M, Goldberg R, Ship AG. Dorsal skin and fingernails on the volar aspect of the hand: an unusual anatomic deformity. Plast Reconstr Surg 1982;69:694-6.

2. Keret D, Ger E. Double fingernails on the small fingers. J Hand Surg 1987;12A:60810.

3. Kinoshita Y, Kojima T, Uchida M, Kurimoto S. Clam nail deformity of the little finger. Plast Reconstr Surg 1993;91:158-61.

4. Beatty E. Upper limb tissue differentiation in the human embryo. Hand Clinics 1985;1:391-403.

5. Wolpert L. Pattern formation in biological development. Sci Am 1978;239:154-64. 